\title{
Factors Associated with full Immunization Coverage amongst children aged 12 - 23 months in Zimbabwe
}

\author{
Tinashe Mukungwa \\ Zimbabwe Open University \\ Faculty of Applied Social Sciences \\ Chiedza House, Kwame Khuruma Ave Harare, Zimbabwe \\ E-mail: tinaitai@gmail.com \\ Phone: 263779638252
}

\begin{abstract}
Zimbabwe adopted the WHO recommendations to fight childhood vaccine preventable diseases in 1980. However coverage of immunization has not been in line with the global target. This study thus utilized the Zimbabwe Demographic and Health Survey (ZDHS) data to analyze the variables of immunization status of children aged 12-23 months in Zimbabwe. A multivariate binary logistic regression analysis of the data was performed. The data consisted of 978 children aged 12-23 months from the selected households. Results showed that children of mothers with secondary education and above were more likely to be vaccinated than children of uneducated mothers. Children of the Ist birth order were more likely to be vaccinated than children of birth order $6+$. The same positive associations were also observed with Delivery in a health facility, antenatal care visits, frequency of watching television, and wealth status. Regional variations in immunization were also established, at significant level $p>0.01$. These results depict the importance of socio-demographic factors in full immunization and call for increased awareness programs in order to promote completion of immunization schedule.
\end{abstract}

Keywords: full immunization, children I2-23 months, factors

\section{Résumé}

Zimbabwe a adopté les recommandations de I'OMS pour lutter contre la vaccination de l'enfance maladies évitables en 1980. Cependant la couverture de la vaccination n'a pas été en ligne avec l'objectif mondial. Cette étude ainsi utilisé le Zimbabwe Enquête Démographique et de Santé données pour analyser les variables de l'état de vaccination des enfants âgés de 12 à 23 mois au Zimbabwe. Un binaire analyse de régression logistique multivariée des données a été réalisée. Les données se composait de 978 enfants âgés de 12 à 23 mois des ménages sélectionnés. Les résultats ont montré que les enfants de mères ayant une éducation secondaire et au-dessus étaient plus susceptibles d'être vaccinés que les enfants de mères sans instruction. Enfants de ler rang de naissance étaient plus susceptibles d'être vaccinés que les enfants de l'ordre de naissance $6+$. Les mêmes associations positives ont également été observés avec livraison dans un établissement de santé, visites prénatales, la fréquence de regarder la télévision, et l'état de la richesse. Les variations régionales en matière de vaccination ont également été établis, au niveau significative $p>0,0 \mathrm{l}$. Ces résultats illustrent l'importance des facteurs sociodémographiques de la vaccination complète et appellent à une augmentation des programmes de sensibilisation dans le but de promouvoir la réalisation des calendrier de vaccination.

\section{Introduction}

In 1980, the new government of Zimbabwe adopted a policy of equity of health geared at addressing the disparities in accessing health services caused by the colonial government (Chandiwana 200I). According to UNICEF (200I), this saw the introduction of free primary health care for all in 1982, initiating the
WHO recommended Zimbabwe Expanded Program of Immunization (ZEPI) to fight against the six major vaccine preventable diseases which are polio, measles, diphtheria, tetanus, and tuberculosis (Ministry of Health and Child Welfare-MoHCW 2005). According to the MoHCW Hepatitis B was added to the list in 1999. The guidelines adopted from WHO requires Bacille Calmette Guerin (BCG) 
vaccination (against tuberculosis), three doses of DPT vaccine, three doses of polio vaccine, and measles vaccine by the age of nine months (ZEPI 2005). With the adoption of antigens that protect against Hepatitis $B$ and Haemophilus influenza, DPT is no longer given as a stand-alone but ZEPI came up with DPT-HBHib vaccine also known as Pentavalent vaccine. This has been given since 2008 (Zimstat 20I2).

UNICEF (2009) reports that, about 8.8 million children under the age of five die annually down from the 1990 figure of 12.5 million. UNICEF attributes this global decline in mortality to increased use of key health interventions such as immunization, the use of insecticide-treated bed nets to prevent malaria, and Vitamin A supplementation. The report adds that where these interventions have increased, positive results have followed. Of these interventions, the Center for Disease Control and Prevention (CDP 1999) ranks immunization as the most crucial and cost-effective public health intervention, and adds that it has successfully saved lives during the 20th Century. In line with this Hartziandrean et al (200I) estimate that for every investment of a dollar on diphtheria, tetanus and pertussis (DPT) vaccination of pre-school children, $\$ 27$ is saved in health and other costs.

ZEPI program saw a remarkable increase in vaccination in Zimbabwe from $25 \%$ in 1982 to $82 \%$ in 1989 (MoHCW 2005). However, 30 years after the initiation of ZEPI, the Ministry of Health has not yet managed to achieve the 200I global target of $90 \%$ immunization coverage of the six EPI vaccinepreventable diseases among children under I year (UNICEF 1996 cited in Murison 2003). This calls for an investigation into the factors hindering full coverage. Full vaccination has instead declined to $64.5 \%$ in 2011 from $80 \%$ in 1994 (Zimstats 20I2). This downward trend is not expected for a country faced with a mammoth task of reducing under-five mortality rates from the current 84 deaths per 1000 live births to 30.8 per 1000 by 2015 in line with MDG 4 requirements. According to $\mathrm{WHO}$ and UNICEF (2007), about $15 \%$ of mortality among children under the age of five is attributed to vaccinepreventable diseases. The situation is even worse in developing countries where $20-35 \%$ of under-five mortality is as a result of vaccine-preventable diseases (Behrman et al 1994, UNICEF 200I, Kalaivan 2006).

\section{Literature Review}

A number of studies have been carried out across the world to find out the significant factors that hinder or increase the likelihood of immunization. Factors that have been found to be significantly associated with vaccination uptake include maternal education and age, socio- economic status, religion, health services utilization and exposure to the media. Research has revealed that children in urban areas are more likely to be fully vaccinated than children in rural areas (Fermandez, Awotess and Ramasha 201I, Patra 2008, Manthal 2007, Mosand and Dixit 2012, Wiysonge et al 20I2). Accessibility to health facilities in rural areas is poor as compared to urban areas. Studies by lbnouf et al (2007) and Rup et al (2008) revealed that immunization was significantly higher where distance to a health facility was lower as the case with urban areas.

Studies have also shown that maternal factors accounted for a high likelihood of child vaccination. Mothers with secondary education and higher are better informed and more empowered hence are more likely than their counterparts with primary or no education to have their children immunized (Pandey and Lee 20II, Nath 2007, Tadesse 2009). Other studies have revealed that Immunization compliance increased with mother's economic status. Mothers with high economic status are more likely to immunize their children than mothers with a poor economic standing (Ozaydin et al 2005, Mosand et al 20I2). Immunization compliance is also higher when mothers previously utilized antenatal care services during pregnancy as well as delivered in health facilities (Babalola 2009, Luma 2005, Etana and Deressa 20II, Pandey and Lee 20II, Masand et al 20I2).

Other research findings have also shown that the likelihood of receiving vaccination for children of 12 23 months is significantly determined by religious beliefs, with children born to Muslim mothers unlikely to be vaccinated as compared to children born to Christian mothers (Nath 2007, Babalola 2009). In a cross sectional study, Kalule-Sabiti et al (2014) concluded that Christians tend to have a Western modernized background than Muslims and African Traditions and therefore are expected to be frequent users of health care services. In a study by $\mathrm{Ha}$ et al(2009) utilizing the MICS (2009) survey data in Zimbabwe, children in apostolic faith affiliated households were almost six percentage points less likely to have BCG immunization and measles vaccination and five percentage points less likely to receive polio vaccination as compared to children in households affiliated to other Christian groups.

In a study carried out by Becker et al (1993) possession of a radio and a television was found to be important determinants of immunization. Possession of these gadgets increased the likelihood of immunization. Duah-Owusu (2004) in a study in Ghana to find the social determinants of immunization concurred with these results and 
concluded that radio and television enhanced access to health information.

With the high under-five mortality in Zimbabwe, full childhood immunization can mitigate morbidity and mortality through prevention of a vaccinepreventable infection. In an effort to improve immunization in Zimbabwe therefore, it is imperative to carry out a study of the factors hindering full immunization of children in order to provide recommendations for policy formulation and designing implementation programs geared at increasing immunization coverage in the country.

\section{Conceptual Framework}

The study applied the hypothetical model of health care utilization which was developed by Andersen (1968) which looks at three categories of determinants namely predisposing, enabling and need characteristics. Predisposing characteristics are individual propensity to use services based on demographic, religious and values concerning health and illness. In this study predisposing characteristics include child's birth order, child's sex, mother's age, marital status, mass media exposure (television, radio, and newspaper), religion, place of delivery, and antenatal care utilization during pregnancy.

Enabling characteristics are resources within the family and community facilitating utilization of health services. In this study enabling characteristics include educational level, wealth status, rural or urban residence, region of residence, and employment status of the mother. The current model excludes need characteristic which define the extent of the need which includes disease severity. The exclusion of need characteristics in this analysis is influenced by absence of data on severity of vaccine preventable diseases in the ZDHS; hence the conceptual framework shown in Fig I below does not include this level of determinants.
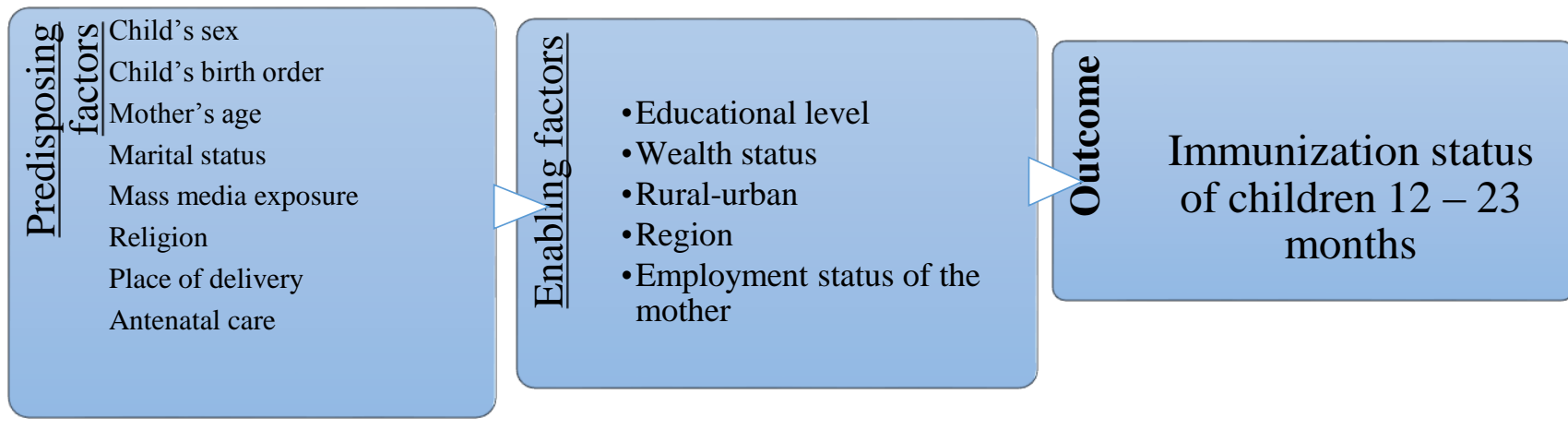

\section{Figure I: Conceptual Framework of Immunization overage among children I 2-23 months in} Zimbabwe

\section{Methodology}

This research utilized data obtained from the Zimbabwe Demographic and Health Survey (ZDHS 20I0-II). The data were collected through a nationwide cross-sectional survey conducted by the Zimbabwe National Statistics Agency (ZimStat) from a representative sample of 9, I7I women aged 15-49 years and 7,480 men aged 15-54 years. Of the 10,166 households identified for the survey, a total of 9,756 were successfully interviewed. The sample included 979 children aged 12-23 months found in the selected households, and of these 49I were male and 488 were female. Seventy two percent of the children were residents of rural areas while 27.7 resided in urban areas. This survey is the fifth such exhaustive survey in the country. The DHS is the principal source of demographic and health data in the country, providing vital data on child health, maternal health, HIV and AIDS, and fertility, and other socioeconomic characteristics. ZDHS data were chosen because they are representative of the national population as a systematic randomly selected representative sample is drawn from the whole population.

The analysis in this study used the children's record data file. The data file contained all the data collected on children aged 0-59 months from women aged 15-49 years selected as study participants. The files were filtered using the SELECT CASE command in SPSS in order to analyses children aged 12-23 months only. The data was adjusted for sampling weights using the variable v005 "Women's individual sample weight", since the variable has 6 decimals, Measure DHS recommends that it be divided by one 
million to come up with v005/I000000. Weighting the data reduced the risk of deriving estimates that are biased towards the over sampled subpopulations.

\section{Defining Dependent variable}

Vaccination information was collected from child health cards and where these were not available the researcher relied on the mother's recall. A child is considered fully vaccinated when he/she has received all the required vaccines. By the age of 12 months a child should be fully vaccinated. Full vaccination was created as a dummy variable by computing the product of all the necessary vaccines which are: BCG, pentavalent/DPT I-3, polio I-3 and measles. Before computation was done the categories were redefined by recording to come up with two categories either 'No' for those not vaccinated or 'Yes' for those whose vaccination record was on the health card and those whose information was recorded from mother's recall. Redefining categories was necessitated by the need to come up with a dichotomous depended variable that can fit into the Binary Regression model.

\section{Defining independent variables}

Socio-economic, demographic and maternal variables such as mother' age, marital status, mother's and father's education, religion, exposure to the mass media, wealth status, birth order, birth type, region of residence and rural-urban residence were included into the regression model as independent variables. The categories were redefined in order to facilitate analysis.

\section{Predisposing Factors}

I. Marital status: Single, Married, Cohabiting, Previously Married

2. Mother's age: 15-24, 25-34, 35-44, 45+

3. Sex of Child: Male, Female

4. Birth order: I, 2-3, 4-5, 6+.

5. Religion: Traditional, Muslim,

6. Apostolic sect, and Other Christian. [NB:

Apostolic sect was included as a separate category because the members have unique characteristic which affect utilization of health services differently from other Christian groups (Ha 20I2)]

7. Distance to health facility: Big problem, no big problem

8. Antenatal care visits: No visits, Less than 4,4 and above

9. Place of delivery: Health facility, Home
10. Frequency of reading newspaper: Not at all, Less frequently and Frequently

II. Frequency of listening to the radio: Not at all, Less frequently and Frequently

12. Frequency of watching television: Not at all, Less frequently and Frequently

\section{Enabling Factors}

13. Region: Manicaland, Mashonaland Central, Mashonaland East, Mashonaland West, Matabeleland North, Matabeleland South, Midlands, Masvingo, Harare, Bulawayo

14. Mother's Educational level: No education, Primary, Secondary and higher.

15. Father's Educational level: No education, Primary, Secondary and higher.

16. Wealth status: Poor, Medium, Rich

\section{Statistical analysis}

The study performed univariate, bivariate and multivariate analyses. Uniariate analysis was performed to describe characteristics of the study population using percentages drawn from frequencies. On the other hand bivariate analysis was performed to analysis the relationship between one independent variable and the dependent variable at a time and multivariate analysis using binary logistic regression analysis was performed to identify significant factors associated with full vaccination among children aged 12-23 months. Logistic regression was chosen because our dependent variable is dichotomous (i.e., binary $0-\mathrm{I}$ ). The logistic function is shown as follows.

$$
\log \left(\frac{p}{1-p}\right)=\beta_{0}+\beta_{1} x_{1}
$$

Where $p$ is the predicted probability of an event occurring, I-P is the predicted probability of the other decision, $x$ is our predictor variable, and $\beta 0$ estimates the log odds and $\beta$ estimates the maximum likelihood, the differential log odds of full vaccination associated with the predictor $\mathrm{x}$. The analysis was performed using SPSS version 15.0 and the results are presented by estimated odds-ratio with $95 \%$ Confidence Interval $(\mathrm{Cl})$. Each set of covariates was entered into the dialog box in stages, starting with socioeconomic predictors, then demographic predictors, and lastly predictors of health seeking behavior. 


\section{Results}

Table I below shows the characteristics of the study sample, the sample consisted of 979 respondents after filtering out those without children of the required age range. Seventy three percent of the respondents reside in rural areas while the remaining $28 \%$ reside in urban areas. The majority of the respondents belong to the Christian religion (46\%) and apostolic sects (46.6). Also most respondents are in the 15-24 (42.4\%) and 25-34 (44.2\%) age groups. In relation to educational attainment, the bulk of the respondents (69.4\%) attained secondary education and higher as compared to only $1 \%$ without education and $29.6 \%$ with primary education. Eighty three percent of the respondents are married, $9 \%$ either divorced widowed, $4 \%$ are single and an equal proportion are cohabiting. In terms of utilization of health services, $62 \%$ of the respondents had four antenatal care visits and above during their last pregnancy, while only $12 \%$ did not receive antenatal care, and $26 \%$ had less than four visits. Sixty one percent of the respondents gave birth in a health facility while $37.5 \%$ delivered at home. In terms of economic status, most respondents (43\%) are in the poor category, while $35 \%$ are rich and $21.5 \%$ are in the middle income category.

Table I: Socio-demographic characteristics of the respondents in the sample

\section{Variables}

\section{Marital Status}

Single

Married

Cohabiting

Previously Married

Mother's age

$15-24$

$25-34$

$35-44$

$45+$

Place of delivery

Home

Health facility

Other

\section{Antenatal care}

No visits

Less than 4

4 and above

Residence

Urban

Rural

Wealth Status

Poor

Medium

Rich

Religion

Traditional

Muslim

Apostolic

Christian

Other

To be fully vaccinated, a child should have received one dose of BCG vaccine, three doses each of pentavalent and polio vaccines, and one dose of

\section{Frequency}

Percentage

39

878

3.7

39

83.4

97

3.7

9.2

446

42.4

465

128

44.2

12.1

13

I.3

395

37.5

642

61

16

I.5

120

264

11.9

629

26

62.1

291

27.7

761

72.3

454

43.1

226

21.5

373

35.4

4

0.4

3

490

0.3

46.6

485

46.1

70

6.6

measles vaccine. Table 2 shows that $65.4 \%$ of children aged 12-23 months had their immunization schedule completed. Eighty eight percent had 
received BCG vaccination, $80 \%$ had received the measles vaccine. Eighty seven percent had received Polio I vaccine; while $83 \%$ had received polio 2 and $75 \%$ had received Polio 3 vaccine. There was a I $2 \%$ drop out between Polio I and Polio 3 vaccine. Eighty seven percent of children had received pentavalent I vaccine, while $82 \%$ and $75 \%$ had received pentavalent 2 and 3 respectively. There was a I2\% drop out between pentavalent $I$ and 3 .

\section{Table 2: Vaccination Coverage of children aged 12-23 months}

\begin{tabular}{|c|c|c|}
\hline Vaccine received & Yes & No \\
\hline BCG & 88 & 12 \\
\hline Polio I & 87.2 & 12.8 \\
\hline 2 & 83 & 17 \\
\hline 3 & 75 & 25 \\
\hline Pentavalent I & 86.7 & 13.3 \\
\hline 2 & 81.9 & I8. 1 \\
\hline 3 & 75 & 25 \\
\hline Measles & 80.2 & 19.8 \\
\hline Full Vaccination & 65.4 & 34.6 \\
\hline
\end{tabular}

Table 3 shows the results of the bivariate analysis of the relationship between full immunization and socio-demographic characteristics. Child's birth order, place of delivery, antenatal care visits during pregnancy, frequency of watching television, region of residence, mother's educational level and wealth status were all strongly associated with full immunization. Sixty nine percent of children of the Ist birth order were fully immunized as compared to $59 \%$ of children of birth order $5-6$ and $45 \%$ of children of the 6th birth order and above. Children delivered at health facilities were more likely to have their immunization schedule completed $(73 \%)$ as compared to children delivered at home (54\%). Seventy percent of children whose mothers had 4 antenatal care visits and above during pregnancy had their immunization schedule completed as compare to $40 \%$ of children whose mothers had no single visit. Frequency of watching television was also an important predictor of full immunization as $74.5 \%$ of children whose mothers watched television less frequently were fully immunized as compared to $59 \%$ of children whose mothers did not watch television at all.

Region of residence was another important factor, as immunization compliance differed with region of residence. Bulawayo and Mashonaland East provinces recorded the highest immunization compliance, with $86 \%$ and $80 \%$ respectively of the children who were fully vaccinated. Manicaland province had the lowest compliance as only $48 \%$ of the children were fully vaccinated. Likelihood of full vaccination also increased with mother's level of education. Seventy one percent of children whose mothers had secondary education and above were fully vaccinated as compared to $54 \%$ of children whose mothers had primary education and $54.5 \%$ of children whose mothers had no education. Seventy five percent of children whose mothers were rich had their immunization schedule completed as compared to $61 \%$ of children whose mothers were in the middle income bracket and $59 \%$ of children whose mothers were poor.

Frequency of reading newspaper, type of residence, religion and distance to a health facility were moderately associated with full immunization. Seventy percent of children whose mothers read the newspaper less frequently were fully immunized as compared to $62 \%$ whose mothers did not read the newspaper at all. Seventy two percent of children resident in urban areas had their immunization schedule completed as compared to $63 \%$ of the children who resided I rural areas. Seventy percent of children whose mothers were Christians were fully vaccinated as compared to $62 \%$ of children whose mothers were affiliated to the apostolic sect. All children whose mothers were of the Islamic religion were fully vaccinated, while $75 \%$ of children whose mothers belonged to the traditional religion were fully vaccinated. Children whose mothers indicated that the distance to the health facility was no big problem were more likely to be fully vaccinated (68\%) as compared to children whose mothers indicated that the distance was a big problem (62\%) 
Table 3: Relationship between full-immunization and Selected Socio-Demographic Variables

\begin{tabular}{|c|c|c|c|c|}
\hline \multirow[b]{2}{*}{ Variables } & \multicolumn{3}{|c|}{ Full Immunization } & \multirow[b]{2}{*}{$\begin{array}{l}\text { Number } \\
\text { children }\end{array}$} \\
\hline & No & Yes & $\begin{array}{l}\text { Pearson } \\
\text { Chi-square }\end{array}$ & \\
\hline \multicolumn{5}{|l|}{ Predisposing Factors } \\
\hline$\overline{\text { Marital Status }}$ & & & 1.738 & \\
\hline Single & 33.3 & 66.67 & & 36 \\
\hline Married & 35.3 & 64.67 & & 815 \\
\hline Cohabiting & 33.3 & 66.67 & & 36 \\
\hline Previously Married & 28.4 & 71.6 & & 88 \\
\hline Mother's age & & & 2.040 & \\
\hline $15-24$ & 44.4 & 55.6 & & 419 \\
\hline $25-34$ & 32.3 & 69.7 & & 427 \\
\hline $35-44$ & 28.2 & 71.8 & & 117 \\
\hline $45+$ & 40.2 & 59.8 & & 13 \\
\hline Sex of child & & & 0.843 & \\
\hline Male & 36 & 64 & & 489 \\
\hline Female & 36.2 & 66.8 & & 488 \\
\hline Birth order & & & 20.395 & \\
\hline 1 & 30.9 & 69.1 & & 301 \\
\hline $2-3$ & 31.3 & 68.7 & & 435 \\
\hline $4-5$ & 41.4 & 58.6 & & 169 \\
\hline $6+$ & 54.9 & 45.1 & & 71 \\
\hline Religion & & & 8.209 & \\
\hline Traditional & 25 & 75 & & 4 \\
\hline Muslim & 0 & 100 & & 3 \\
\hline Apostolic & 38.3 & 61.7 & & 454 \\
\hline Christian & 30.3 & 69.7 & & 446 \\
\hline Distance to facility & & & 2.859 & \\
\hline Big problem & 37.6 & 62.4 & & 415 \\
\hline Not a problem & 32.4 & 67.6 & & 562 \\
\hline Place of delivery & & & 34.864 & \\
\hline Home & 45.8 & 54.2 & & 371 \\
\hline Health facility & 27.2 & 72.8 & & 591 \\
\hline Antenatal care visits & & & 36.165 & \\
\hline No visits & 59.6 & 40.4 & & 114 \\
\hline Less than 4 & 33.9 & 66.1 & & 245 \\
\hline 4 and above & 30.4 & 69.6 & & 586 \\
\hline Television & & & 25.792 & \\
\hline Not at all & 41.1 & 58.9 & & 564 \\
\hline Less frequent & 25.5 & 74.5 & & 412 \\
\hline Frequently & ------ & ------- & & ------ \\
\hline Radio & & & 1.610 & \\
\hline Not at all & 36.7 & 63.3 & & 444 \\
\hline Less frequent & 32.8 & 67.2 & & 533 \\
\hline Frequently & ------. & ------- & & ------ \\
\hline Newspaper & & & $5.25 I$ & \\
\hline Not at all & 37.2 & 62.9 & & 618 \\
\hline Less frequent & 30 & 70 & & 357 \\
\hline Frequently & ------- & ------- & & ------ \\
\hline
\end{tabular}


Table 3: Continued

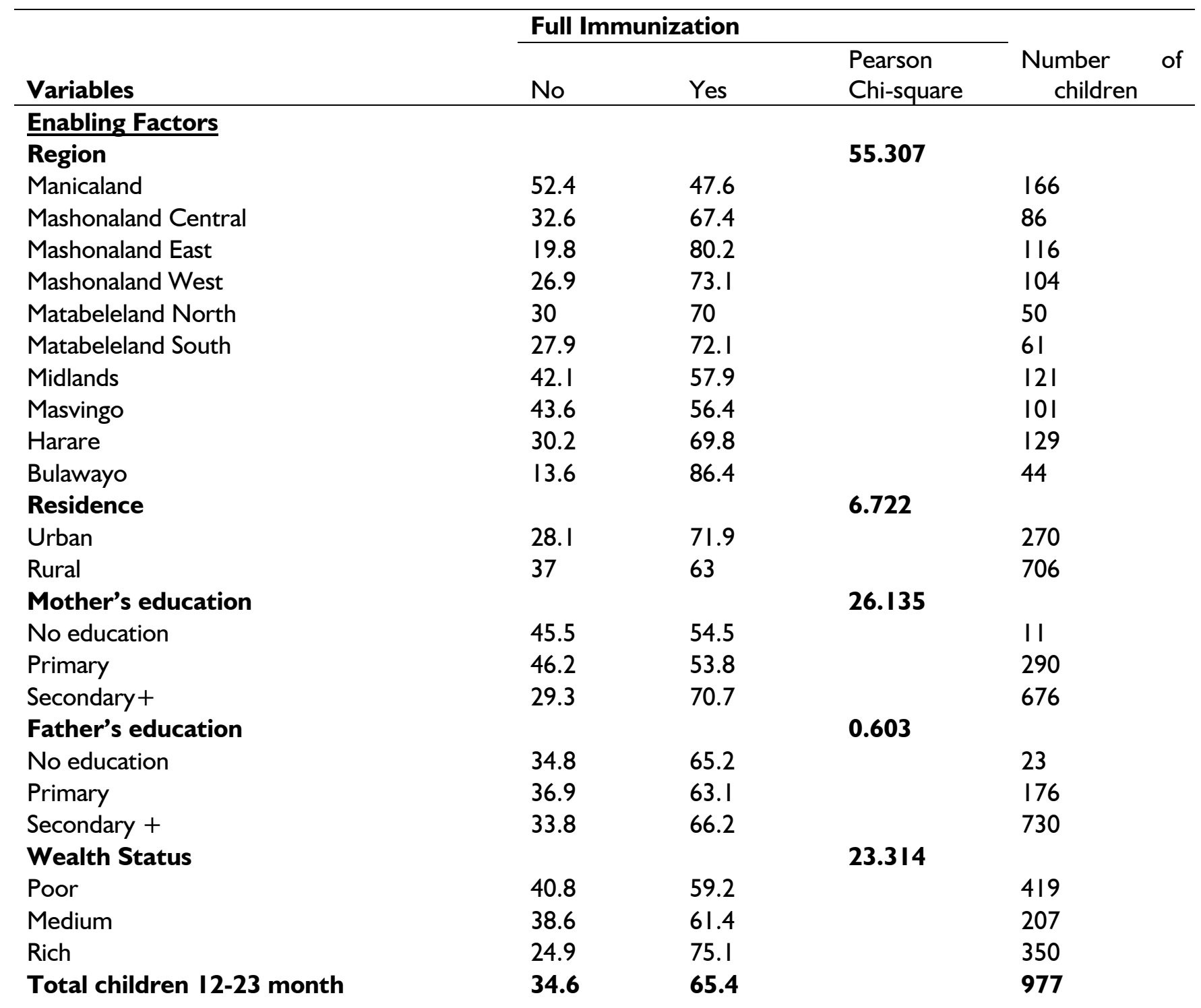

Multivariate results show that some factors such as region of residence, wealth status, birth order, place of delivery, antenatal care during pregnancy, and exposure to television are significant determinants of full vaccination among children aged 12-23 months in Zimbabwe.

\section{Predisposing factors}

Tables 4 shows multivariate results of factors associated with full immunization of children aged I224 months. Birth order showed a significant effect on the likelihood of full immunization. Children of the first birth order were 5 times more likely to be vaccinated than children of birth order 6 and above, and children of birth order 2-3 were 4 times more likely to be vaccinated than children of birth order $6+$. Children of birth order 4-5 were 2 times more likely to be vaccinated than children of birth order $6+$.Maternal age was a significant determinant of full immunization. Mothers in the age group 35-44 were
2 times more likely to have their children vaccinated than children of mothers in the age group 15-24. Children whose mothers were in the age group 2534 were 1.5 times more likely to be vaccinated, than children whose mothers were in the age group 1524.

Place of delivery had a positive significant association with full vaccination. Children who were delivered in health facilities were 2 times more likely to be vaccinated than children who were delivered at home. Ante-natal care is another variable that was found to have a positive association with full vaccination. Children whose mothers had 4 and above ante-natal care visits were 3 times more likely to be vaccinated than children whose mothers did not receive ante-natal care. Children whose mothers had less than 4 ante-natal care visits were more than 2 times more likely to be fully vaccinated than children whose mothers did not receive ante-natal care. Exposure to mass media was also found to be 
an important predictor of full vaccination. Children whose mothers watched television less frequently were 2 times more likely to be vaccinated than children whose mothers did not watch television at all.

Table 4: Logistic Regression Analysis of the of socioeconomic variables

\begin{tabular}{|c|c|c|c|}
\hline \multirow[t]{2}{*}{ Variables } & \multirow[t]{2}{*}{$\operatorname{Exp}(B)$} & \multicolumn{2}{|c|}{$95.0 \%$ C.I. for EXP(B) } \\
\hline & & Lower & Upper \\
\hline \multicolumn{4}{|c|}{$\frac{\text { Predisposing Factors }}{\text { Marital Status }}$} \\
\hline Single & $\operatorname{Ref}(1.00)$ & & \\
\hline Married & .963 & .470 & 1.973 \\
\hline Cohabiting & .979 & .361 & 2.650 \\
\hline Previously Married & 1.230 & .530 & 2.857 \\
\hline \multicolumn{4}{|l|}{ Mother's age } \\
\hline $15-24$ & $\operatorname{Ref}(1.00)$ & & \\
\hline $25-34$ & $1.519 *$ & 1.067 & 2.163 \\
\hline $35-44$ & $1.919 *$ & 1.079 & 3.414 \\
\hline $45+$ & 3.404 & .941 & 12.313 \\
\hline \multicolumn{4}{|l|}{ Sex of child } \\
\hline Male & $\operatorname{Ref}(1.00)$ & & \\
\hline Female & 1.153 & .881 & 1.508 \\
\hline \multicolumn{4}{|l|}{ Birth order } \\
\hline I & $4.822 * * * *$ & 2.418 & 9.619 \\
\hline $2-3$ & $3.927 * * *$ & 2.111 & 7.307 \\
\hline $4-5$ & $1.99 \mid *$ & 1.097 & 3.613 \\
\hline $6+$ & $\operatorname{Ref}(1.00)$ & & \\
\hline \multicolumn{4}{|l|}{ Religion } \\
\hline Traditional & $\operatorname{Ref}(1.00)$ & & \\
\hline Muslim & 1.429 & .016 & 125.316 \\
\hline Apostolic & .534 & .052 & 5.495 \\
\hline Christian & .667 & .064 & 6.924 \\
\hline \multicolumn{4}{|l|}{ Distance to facility } \\
\hline Big problem & $\operatorname{Ref}(1.00)$ & & \\
\hline Not a problem & .922 & .667 & 1.275 \\
\hline \multicolumn{4}{|l|}{ Place of delivery } \\
\hline Home & $\operatorname{Ref}(1.00)$ & & \\
\hline Health facility & I.798*** & 1.272 & 2.542 \\
\hline \multicolumn{4}{|l|}{ Antenatal care } \\
\hline No visits & $\operatorname{Ref}(1.00)$ & & \\
\hline Less than 4 & $2.474 * * *$ & 1.465 & 4.178 \\
\hline 4 and above & $2.834^{* * * *}$ & $\mathrm{I} .742$ & 4.609 \\
\hline \multicolumn{4}{|l|}{ Television } \\
\hline Not at all & $\operatorname{Ref}(1.00)$ & & \\
\hline Less frequent & $1.628^{* *}$ & 1.127 & 2.351 \\
\hline Frequently & -------- & ------- & -------- \\
\hline \multicolumn{4}{|l|}{ Radio } \\
\hline Not at all & $\operatorname{Ref}(1.00)$ & & \\
\hline Less frequent & .959 & .688 & 1.335 \\
\hline Frequently & -------- & -------- & ------- \\
\hline \multicolumn{4}{|l|}{ Newspaper } \\
\hline Not at all & $\operatorname{Ref}(1.00)$ & & \\
\hline Less frequent & .884 & .619 & 1.263 \\
\hline Frequently & -------- & -------- & -------- \\
\hline
\end{tabular}


Table 4: Continued

\begin{tabular}{|c|c|c|c|}
\hline \multirow[t]{2}{*}{ Variables } & \multirow[t]{2}{*}{$\operatorname{Exp}(B)$} & \multicolumn{2}{|c|}{ 95.0\% C.I. for EXP(B) } \\
\hline & & Lower & Upper \\
\hline \multicolumn{4}{|l|}{ Enabling Factors } \\
\hline \multicolumn{4}{|l|}{ Region } \\
\hline Manicaland & $\operatorname{Ref}(1.00)$ & & \\
\hline Mashonaland Central & $2.659 * * *$ & $\mathrm{I} .467$ & 4.817 \\
\hline Mashonaland East & $4.22 I^{* * * *}$ & 2.374 & 7.505 \\
\hline Mashonaland West & $2.745 * * *$ & 1.523 & 4.947 \\
\hline Matabeleland North & $2.795 * *$ & 1.237 & 6.314 \\
\hline Matabeleland South & $3.030 * *$ & 1.363 & 6.734 \\
\hline Midlands & 1.598 & .951 & 2.687 \\
\hline Masvingo & 1.470 & .852 & 2.537 \\
\hline Harare & $2.652 * *$ & 1.329 & 5.294 \\
\hline Bulawayo & $5.356 * * *$ & 1.760 & 16.296 \\
\hline \multicolumn{4}{|l|}{ Residence } \\
\hline Urban & $\operatorname{Ref}(1.00)$ & & \\
\hline Rural & .596 & .325 & 1.094 \\
\hline \multicolumn{4}{|l|}{ Mother's education } \\
\hline No education & $\operatorname{Ref}(1.00)$ & & \\
\hline Primary & 1.148 & .290 & 4.547 \\
\hline Secondary+ & $2.06 I^{* *}$ & 1.217 & 8.208 \\
\hline \multicolumn{4}{|l|}{ Father's education } \\
\hline No education & $\operatorname{Ref}(1.00)$ & & \\
\hline Primary & .651 & .204 & 2.073 \\
\hline Secondary + & .681 & .217 & 2.135 \\
\hline \multicolumn{4}{|l|}{ Wealth Status } \\
\hline Poor & $\operatorname{Ref}(1.00)$ & & \\
\hline Medium & .986 & .665 & $\mathrm{I} .463$ \\
\hline Rich & $2.270 * * *$ & 1.407 & 3.662 \\
\hline
\end{tabular}

\section{Enabling factors}

Table 4 shows the results of the enabling factors. Region of residence was found to have a statistically significant association with full vaccination. Children residing in Bulawayo province were 5 times more likely to be vaccinated than children in Manicaland province. Children whose residence was in Harare were 3 times more likely to be vaccinated than children in Manicaland province. Children whose residence was in Matabeleland South province were 3 times more likely to be vaccinated than children in Manicaland. Children in Matabeleland North were 3 times more likely to be vaccinated than children in Manicaland province. The odd of being vaccinated were also 3 times higher in Mashonaland West than in Manicaland province. Children who resided in Mashonaland East province were 4 times more likely to be vaccinated than children in Manialand, The odds of full vaccination were also 3 times more in Mashnaland Central than in Manicaland.

Mother's educational level was significantly associated with full immunization. Children of mothers with secondary education and higher were 2 times more likely to be fully vaccinated than children with uneducated others. Wealth status was also associated with full vaccination. Children of mothers who were rich were 2 times more likely to receive full vaccination than children whose mothers were poor.

\section{Discussion}

The study attempted to assess the factors affecting immunization coverage among children aged 12-23 months in Zimbabwe. The study is limited to crosssectional data and hence cannot determine causality. Zimstat (2012) recorded immunization using vaccination cards and maternal recall. Sixty eight percent of all the children aged 12-23 months had vaccination cards. By the age of 12 months in Zimbabwe a child is expected to have received all the required vaccines. Twelve percent drop out between Polio I vaccine and Polio 3 vaccine, and between Pentavalent $I$ vaccine and Pentavalent 3 vaccine 
reflects lack of knowledge in the relevance of receiving the boosters. This knowledge should be clearly disseminated to the mothers by the health workers at the time of receiving the first vaccine.

The study found out that birth order was an important predictor of full immunization. This is likely so because for the lower birth order children, mothers are enthusiastic about having children and they exert appropriate care and upbringing of the children. Patra (2006) argues that caregiver's negligence affect immunization of higher order children. Patra (ib id) goes on to say that mothers become apathetic when it comes to immunization of children of higher order. This realization calls for a scaling up of awareness for family planning in order to reduce the number of children in a household.

Mothers of middle ages 25-34, and 35-44 were more likely to fully immunize their children than younger mothers. Maternal age is an important determinant of full immunization. The propensity to immunize children by older mothers $45+$ years was also lower. The median age of child bearing in Zimbabwe is 26 years (Zimstat 2007), hence lower birth order children are expected at middle ages. For the older mothers, parity is likely to be higher; hence the likelihood of immunization diminishes. For the younger mothers however, although parity is lower, they are likely to be affected by lack of experience. Family planning can mitigate this factor by delaying child bearing at young maternal age and limiting child bearing at old maternal age.

Place of delivery and antenatal care visits were other important predisposing factors of immunization. These depict the availability and accessibility of health facilities. BCG vaccine for instance is administered soon after birth, so a child born in a health facility will more likely receive this vaccine. The mother becomes better informed about immunization such that she is more likely to have her child receive other vaccines. A mother who delivers in a health facility is more likely to receive training from health professionals on the importance of vaccination. These findings are in line with the results of the research by Mosand et al (2012) who also found out that those children born in health facilities were more likely to be fully vaccinated than children born in non-health facilities. Health professionals also take advantage of antenatal care visits to increase awareness of proper child care by mothers. Also visual aids like charts promoting proper child care are available at ante-natal care clinics. These findings are in agreement with the findings by Pandey and Lee (20II) who found out that mothers who received ante-natal care were 3 times more likely to immunize their children than mothers who did not.
Awareness of the importance of vaccination increases the propensity of vaccination. The likelihood of completing the immunization schedule was higher for mothers with secondary education and higher than for mothers without formal education. The likelihood was also higher among mothers who watched television than those who did not. Mothers with secondary education and higher and those exposed to television are more aware of the benefits of immunization, since they have access to relevant information, hence the likelihood of their children completing the vaccination schedule is higher. Research has also shown that the propensity to vaccinate children increases with the level of education (Nath 2007, Pandey and Lee 20II). Caldwell (1989) cited in Kembo (2009) noted that education supplies women with the knowledge and skills required to raise healthy children.

In line with other studies (Ozaydin et al 2005, Mosand et al 2012), this study managed to establish that children from wealthier households are more likely to be vaccinated than children from poor households. However there was no difference in propensity to vaccinate between children from middle income households and poor households. Children form wealthier families are more likely to visit health facilities more frequently for medical check-up. In the process their vaccination statuses are checked by health professionals and receive missing doses. The middle income group is usually the working class and hence the mothers may fail to find time to take their children for vaccination. On the other hand poor mothers may fail to afford to utilize healthcare services for their children. Results of the study held by Wiysonge et al (2012) nonetheless showed a negative association, he found out that children born in poor households were $36 \%$ more likely to be vaccinated than children born in wealthier families.

Marital status was not a significant predictor of full vaccination. This implies $t$ full vaccination does not depend of marital status. Also unlike other studies (Ha et al 2009, Nath 2007, Antai 2009), this study could not establish a significant association between religion and full vaccination. $\mathrm{Ha}$ et al 2009 had established a strong association between religion and vaccination against measles in Zimbabwe. He found out that children whose mothers belonged to apostolic faith churches were less likely to receive measles vaccine as compared to other Christian groups. Efforts have been made to raise health awareness among members of apostolic churches through the Union for the Development of Apostolic Churches in Zimbabwe (UDACIZA). With the exception of the Johanne Marange sect (Chiketo 20I2), the health awareness projects by UDACIZA 
aimed at eradicating ignorance amongst apostolic churches have proved to be effective showing us the importance of awareness programs

The study established a strong relationship between region of residence and full vaccination. Regions consist of different adult literacy rates and levels of development. Bulawayo region has higher levels of adult literacy than Manicaland and other largely rural regions (Zimstat 20I2) hence the higher proportions of full immunization. The other factor is that the province is an urban province hence caregivers have better access to vastly available health facilities. Unexpectedly however, Mashonaland West region which is largely rural has a higher proportion of fully immunized children than Harare. Harare, though an urban region with a higher literacy level, shares equal proportion of fully immunized children with some largely rural regions (Matebeleland North and South, Mashonaland West and Central). Harare has been affected by the sprouting of unplanned slum settlements where health facilities are scarcely available. It was also established that other equally rural regions were 3 times more likely to have fully vaccinated children than Manicaland region. Manicaland has the highest concentration of members of the Johanne Marange sect who are highly opposed to healthcare in favour of prophetic healing through prayer (Zimbabwe News Update, May 23 2010; The Standard, April 28 2012)

Type of residence could not significantly affect full immunization. The closing of the gap of full immunization between rural and urban areas in Zimbabwe could be due to increased distribution of health facilities in rural areas aimed at removing discrepancies between rural and urban areas in Zimbabwe. Since independence the government has scaled up efforts to construct health facilities in rural areas to better improve access by the rural folks. However, the result was not consistent with the findings by Munthal (2007) and Mermandez et al (20II) who established that children in urban areas are more likely to be fully vaccinated than children in rural areas.

\section{Conclusion recommendation}

All in all this study has established the roles played by some predisposing factors and enabling factors in determining full immunization. Full immunization was associated with child's birth order, mother's educational level and wealth status, region, frequency of watching television, place of delivery and antenatal care visits. It is recommended that family planning programs should be aimed at educating men and women in rural areas and of low educational levels of the benefits of using birth limiting methods to reduce parity. It is further recommended that the Ministry of Health and Child Care should work in partnership with Non-Governmental organization in implementation of the Zimbabwe Expanded Program of Immunization in remote areas. The poor people in these areas find it a challenge to afford healthcare for vaccination. Community awareness programs should be scaled up by incentivizing community health workers. This will benefit especially those who failed to deliver in health facilities. Availing communities with information required to improve awareness is more likely to improve vaccination. It is also recommended that urban councils formalize unplanned settlements so as to facilitate availability of social amenities like healthcare facilities. Appropriate strategies and interventions should therefore be formulated. Child health interventions should be scaled up by means of increasing budgetary allocation to the Zimbabwe Expanded Program of Immunization (ZEPI).

Additional research is required to gather an indepth, qualitative knowledge on the barriers to full immunization. This will give policy makers an indepth understanding other than the pre-coded responses of the ZDHS data. A more qualitative analysis could uncover interesting insights around the established factors.

\section{References}

Antai, D. (2009). Faith and child survival: the role of religion in childhood immunization in Nigeria. Journal of Biosocial Science, 4I(0I), 57-76.

Babalola, S. (2009). Determinants of the Uptake of the Full Dose of Diphtheria-Pertussis-Tetanus Vaccines (DPT3) in Northern Nigeria: A Multilevel Analysis. Maternal Child Health Journal 13, 550558.

Behrman RE, Kliegman RM, Arvin AM. Textbook of Pediatrics. 15th ed. Philadelphia: W B Saunders; 1994. p. 1020.

Becker, $S$ et al: The determinants of use of maternal and child health services in Metro Cebu, the Philippines. Health Transition Review, 1993. 3(I), 77-89.

Chandiwana S.K: Striving to Safeguard Health Systems Undermined by Adjustment: Policy Lessons from Zimbabwe The International Development Research Centre- Science for Humanities.200I

Centers for Disease Control and Prevention. Impact of vaccines universally recommended for children- United States, 1990-1998. MMWR Morb Mortal Wkly Rep. 1999; 48(I2):238-243. 
Caldwell J.C (1989) Cited in Kembo J: Socio and Economic factors influencing Under-Five Mortality in Zimbabwe during 1996-2005 (PhD Thesis) University of Pretoria Sept 2009.

Etana B, Deressa W: Factors Affecting Immunization Status of Children Aged 12-23 Months in Ambo Woreda, West Shewa Zone of Oromia Regional State: Addis Ababa University College Of Health Science, 20I I

Fernandez RC, Awofeso N, Rammohan A: Determinants of apparent rural-urban differentials in measles vaccination uptake in Indonesia, Rural and Remote Health, II, 20 I I: 1702.

Global Alliance for Vaccines and Immunisation (GAVI): Child immunisation to avert 4 million deaths by 2015, says Gavi report (2013) http://www.theguardian.com/global-

development/2013/oct/30/child-immunisationavert-4-million-deaths-gavi-vaccine

Ha W, Salama P, Gwavuya S and Kanjala C: Equity and Maternal and Child Health - Is Religion the Forgotten Variable? Evidence from Zimbabwe: UNICEF 2012

Hatziandreau EJ, Brown RE, Halpern: Cost Benefit Analysis of the Diphtheria-Tetanus-Pertussis (DTP) Vaccine. Final Report Prepared for the National Immunization Program, Centers for Disease Control and Prevention. Arlington, VA: Battelle Medical Technology Assessment Program; 1994. Center for Public Health Research and Evaluation

Ibnouf A, Van den Borne H, Maarse J.: Factors influencing immunisation coverage among children under five years of age in Khartoum State, Sudan SA Fam Pract 2007 49(8): I 4c-f.

Kalule-Sabiti I, Amoateng A.Y and Ngake M: The Effect of Socio-demographic Factors on the Utilization of Maternal Health Care Services in Uganda: African Population Studies, Vol. 28, No. I, April 20I4

Ministry of Health and Child welfare: Zimbabwe Expanded Programme on Immunisation- Policy Document, 2005

Munthal A.C: Determinants of vaccination coverage in Malawi: Evidence from the demographic and health surveys: Malawi Medical Journal, Vol. 19 (2) 2007: pp. 79-82

Masand R, Dixit AM, Gupta RK: Study of immunisation status of rural children (12-23 months age) of district Jaipur, Rajasthan and factors influencing it: a hospital based study, Journal of Indian Med Assoc. 2012 Nov; I I (I I):795-9.
Nath B: A study on determinants of immunization coverage among 12-23 months old children in urban slums of Lucknow district, India, India Journal of Medical Science 2007- Volume : 6I, Issue : I I, Page : 598-606

Topuzoglu A, Ozaydın G.A.N, Cali S, Cebeci D, Kalaca $\mathrm{S}$ and Harmanci $\mathrm{H}$ : Assessment of sociodemographic factors and socio-economic status affecting the coverage of compulsory and private immunization services in Istanbul, Turkey, Journal of Public Health, Volume 119, Issue 10, October 2005, Pages 862-869

Rup KP, Manash PB, Jagadish M.: Factors Associated with Immunization Coverage of Children in Assam, India: Over the First Year of Life. Journal of Tropical Paediatrics 2008;52(4):249-52.

Patra N: Exploring the Determinants of Childhood Immunisation: Economic and Political Weekly, VOL 43 No. 12 March 22 - April 4, 2008

Patra N: Universal Immunization Programme in India: The Determinants of Childhood Imuunisation, presented at the 42nd Annual Conference (5-7 Jan, 2006) of The Indian Econometric Society (TIES), held at GND Univ., Amritsar, India. http://ssrn.com/abstract $=88 \mathrm{I} 224$

Pandey S, Lee H: Determinants of child immunization in Nepal: The role of women's empowerment. Health Education Journal, On-line first, Sept 20I I doi: I0.1I77/00178969||419343

Sanou A, Simboro S, Kouyate B, Dugas M, Graham J: Assessment of factors associated with complete immunization coverage in children aged 12-23 months: a cross-sectional study in Nouna district, Burkina Faso, BMC International Health and Human Rights, 2009, 9:SI0,

UNICEF : Growing up in Zimbabwe, Harare UNICEF 1999: 108

UNICEF: The Progress of Nations, UNICEF New Yolk 2009

Wiysonge CS, Uthman OA, Ndumbe PM, Hussey GD: (2012) Individual and Contextual Factors Associated with Low Childhood Immunisation Coverage in Sub-Saharan Africa: A Multilevel Analysis. PLoS ONE 7(5): e37905. doi: 10.137IWorld Health Organization

(WHO) (2010). Department of Vaccines and Biological. WHO Vaccines for Preventable Diseases: Monitoring System. Geneva: WHO.

World Health Organization, United Nations Children's Fund. The state of the world's children. Geneva; UNICEF; 200I. p. 77-89.

ZimStat : Zimbabwe Demographic Health Survey (DHS) 1994, Harare Zimbabwe, 1995 
Zimstat 2012: Census 2012 preliminary report, Harare Zimbabwe

ZimStat : Zimbabwe Demographic Health Survey (DHS) 2005-06, Harare Zimbabwe, ICF International, Inc USA, 2007

ZimStat : Zimbabwe Demographic Health Survey (DHS) 2010-11, Harare Zimbabwe, ICF
International, Inc USA, 2012

Bernard Chiketo: Religion in Zimbabwe Some Johanne Marange members see their children as bricks, September 27, 2012 http://relzim.org/forum/religion-and-societyblog/5338/I I 46 . 